\title{
Knowledge of Infection Related to Prolonged Catheter among the B.Sc Nursing Students of Hi- Tech College of Nursing
}

\author{
Bulu Mahanty ${ }^{1}$, Gopabandhu Mishra ${ }^{2}$ \\ ${ }^{1}$ Assistant Professor, Department of Community Medicine, Hitech Medical College \& Hospital , Odisha-25. \\ ${ }^{2}$ Ex Prof. P.G. Department of Statistics Utkal University, Vanivihar.-751004
}

\begin{abstract}
Infection is the invasion of an organisms body tissues by disease causing agents, catheters are medical devices that can be inserted in the body to treat disease or to perform a surgical procedure. Catheter can be inserted into body cavity duct or vessels. Functionally they allow drainage administration of fluid or gases, access by surgical instruments and also perform a wide variety of other tasks depending on the type of catheter. Objectives: To assess the knowledge \&develop the prevention of infection related to prolonged catheter. Evaluate the effectiveness of planned teaching programme regarding prevention of infection related to prolonged catheter. Materials \& Methods: the present study was taken up in Hi-tech medical college\& hospital. Fifty nursing students participated in face to face interview through a Questionnaire. Results : The socio-demographic information's depicts the Maximum 48(96\%) students belong to age group 20-22,Female 47(94\%), 90\% in Hindu Religion, Pre-test knowledge score, percentage of knowledge of student regarding infection related to prolonged catheterization. They are having on average $58.5 \%$ knowledge on this infection related to prolonged catheterization. Pre-test level of knowledge of student regarding infection related to prolonged catheterization. Nursing students were $52 \%$ \& $48 \%$ knowledge of good \& average. Post-test level of knowledge scores $98 \%$ of student regarding infection related to prolonged catheterization. Knowledge student regarding infection related to prolonged catheterization. $20 \%$ of them having excellent knowledge, $74 \%$ of them having good knowledge and $6 \%$ of them are in average. Conclusion: The nursing student had knowledge of infection related to prolonged catheter, and their attitudinal approach towards the betterment of the work environment is positive after the Effectiveness of planned teaching programme.
\end{abstract}

Keywords: Infection, Prolonged catheter, Descriptive Statistics, Chi Square test , Paired t test.

\section{Introduction}

Health Care Associated Infection (HCAI) especially Nosocomial infection (NCI) in ICUs has remained a major cause of mortality and morbidity. Infection related to prolonged catheterization are the most common type of hospital acquired infection accounting for more than $40 \%$ of all nosocomial infection (parker 2009), catheter associated infection has been associated with increased morbidity mortality hospital cost and length of stay.

Infection is the invasion of organisms body tissues by disease causing agents, their multiplication and the reaction of host tissues to these organisms and toxins they produce infectious disease also known as transmissible disease or communicable disease is illness resulting infection.

Nosocomial or hospital acquired infection are called Health Care Associated Infections. Urinary tract infection and central line infections are the most frequent health care associated infection. A urinary tract infection (UTI) occurs because catheter stays in place for an extended period of time, it is called as indwelling catheter. The urine drains from bladder into a bag outside your body.

Whereas the central line is a long tube (catheter) that goes into a vein in your chest, arm or groin and ends at your heart. Your central line will carry nutrients and medicine into your body. It can also be used to take blood when your need to have blood tests.
UTI and central line infections are very serious. They can make you sick and increase how long you are in the hospital. Your central catheter and urinary catheter needs special care to prevent infection.

According to the literature, about $30 \%$ of ICU patients suffer from some kind of infections and there patient will encounter increased ICU length of stay morbidity mortality and cost. The most common isolated pathogens for infection are staphylococcus aureus and acinetobater species with the rates of $30.9 \%$ and $26.8 \%$ respectively. Acinetobacter is considered as the most common gram negative organism colonizes in the skin of hospital care providers, including ICU nurses and respiratory therapists.

Proper techniques of catheter insertion, catheter maintenance and the proper use of catheter material will reduce the rate of catheter associated infection. Prolonged catheterization is catheterization is used in pre-op periods. Duration of catheterization is the major risk factors.

These infections can results in sepsis, prolonged hospitalization, additional hospital costs and morbidity (Elepern 2009). Commonly used management option for older people and short term. In non-acute care settings clean techniques used for intermittent catheterization is an acceptable and more practical alternative to sterile technique for patients requiring chronic intermittent catheterization (HICPAC 2009).The majority of the existing research on catheter related infection has been conducted in acute care setting where catheter usually remain in place for $<14$ days 


\section{International Journal of Science and Research (IJSR) \\ ISSN (Online): 2319-7064 \\ Index Copernicus Value (2013): 6.14 | Impact Factor (2014): 5.611}

and the health of many patients is already compromised by co-morbidities.

Infection is the invasion of organism's body tissues by disease causing agents, their multiplication and the reaction of host tissues to these organisms and toxins they produce infectious disease also known as transmissible disease or communicable disease is illness resulting infection.

For the hospital the highest effectiveness of prolonged catheter infection preventive care on drainage system can improve current practice and the quality of care. The hospitalization length of stay for managing prolonged catheter infection also be reduced. knowledge about prevention of infection related to prolonged catheter, identify the effectiveness of planned teaching programme regarding prolonged catheter.

\section{Material \& Methods}

The present study was taken up in the Hi-tech College of Nursing - a combination of several methods was used to assess the Knowledge of workers. Data collection was done by interviewing the Nursing student through design of questionnaire for interview schedule in English . SocioEconomic background, knowledge prolonged catheter . Sample was taken through simple random sampling techniques with lottery method of sample size Fifty BSc. nursing students. Data were gather through Microsoft Excel Sheet version 2007 \& Statistical analysis was done using SPSS 22.0 .

\section{Statistical Analysis}

Data analysis related to pre-test \& post test with a intervention to knowledge of student regarding Analysis are a process of organizing \& synthesizing data in such a way research questions can be answered.

The result of 50 Nursing students studying HCON B.Sc. Nursing $3^{\text {rd }}$ year assessed demographic variables. Related to age group, maximum $96 \%$ students belong to age group 1822 and minimum 4\% belong to the age 23-27.According to gender, maximum 94\% students were female and $6 \%$ students were male. According to religion, majorities $90 \%$ students were Hindu, 6\% students were Christian and only 4\% students were Muslim. According to marital status, maximum 92\% students were unmarried and minimum $8 \%$ students were married.

Finding related to pre-test knowledge score of the nursing student regarding infection related to prolong catheter that $48 \%$ of them having average knowledge and $52 \%$ of them having good knowledge and none of them having poor and excellent knowledge. They are having 59.65\% knowledge on infection related prolonged catheterization.

Finding related to post-test knowledge score of nursing students regarding infection related to prolonged catheterization that $74 \%$ students have the good knowledge, $20 \%$ students having excellent knowledge and only 6\% student having average knowledge. They are having on an average $98 \%$ knowledge on infection related to prolong catheterization.

In relation to analysis of effectiveness of planned teaching programme regarding infection relation to prolonged catheterization, Considering knowledge, pre-test, nursing student scored 9.86 out of 20 score and in post-test they have scored 17.8 out of 20 score. So there is difference 7.9. The difference between pre-test post-test knowledge score is large and it is satisfactory significant.

\begin{tabular}{|c|c|c|c|c|c|c|c|c|}
\hline & \multicolumn{5}{|c|}{ Paired Differences } & \multirow{3}{*}{ paired "t" test } & \multirow{3}{*}{ d.f. } & \multirow{3}{*}{$\begin{array}{l}\text { Sig. (2- } \\
\text { tailed) }\end{array}$} \\
\hline & \multirow[t]{2}{*}{ Mean } & \multirow[t]{2}{*}{ Std. Deviation } & \multirow[t]{2}{*}{$\begin{array}{l}\text { Std. Error } \\
\text { Mean }\end{array}$} & \multicolumn{2}{|c|}{$\begin{array}{c}\text { 95\% Confidence Interval of the } \\
\text { Difference }\end{array}$} & & & \\
\hline & & & & Lower & Upper & & & \\
\hline $\begin{array}{c}\text { Pre-test \& } \\
\text { post-test }\end{array}$ & 7.9 & 2.38 & 0.34 & 8.6 & 7.2 & 23.431 & 49 & 0.001 \\
\hline
\end{tabular}

The statistics given under the label Paired Differences are calculated by computing the differences between the paired values . The mean, standard deviation \& standard error of mean of these differences along with $95 \%$ confidence interval for the mean of differences are given . The results show a t-statistics of 23.43 with 49 degrees of freedom. The two tailed p- values is 0.001 , which is less than the conventional 5\% level of significance. Therefore, we can reject the null hypothesis at $5 \%$ LOS , which means that the average output of the knowledge of infection related to prolonged Cather among the BSc. Nursing has indeed changed after attending the training program .

\begin{tabular}{|l|c|c|}
\hline \multicolumn{3}{|c|}{ Test Statistics } \\
\hline & Pre-test & Post-test \\
\hline Chi-Square & 13.720 & 24.520 \\
\hline df & 8 & 8 \\
\hline Asymp. Sig. & .089 & .002 \\
\hline
\end{tabular}

From the above Test Statistics of Chi-Square gives $\left(\chi_{0.05}^{2}\right.$ ,49=13.72, $p-$ value $=0.08$, not significant) the pre-test score are not association between the knowledge of infection related to prolonged Cather, after a intervention(training) have given to the BSc. Nursing students then the test statistics gives $\left(\chi_{0.05}^{2}, 49=24.52, p-\right.$ value $=0.002$, Significant) the knowledge of infection related to prolonged Cather has statistically significant .

\section{Summary \& Conclusion}

The nursing student had knowledge of infection related to prolonged catheter, and their attitudinal approach towards the betterment of the work environment is positive after the Effectiveness of planned teaching programme. 
Effectiveness of planned teaching programme regarding infection related to prolonged catheterization. With mean 9.86 \pm 2.07 \& Effectiveness of planned teaching programme, the percentage of gain before and after the planned teaching programme considering knowledge score. Pre test (58.5\%) post-test (97.5\%) \& \% change 39\%.

From this above statistical test (paired t-test \& Chi-Square test) gives there was highly significant, that means best result after the training programme given to the nursing students.

The above study clearly indicate that although 50 nursing students regarding knowledge of infection related to prolonged Cather towards the betterment of the work environments is positive.

\section{Recommendations}

On the basis of the findings of the study, the following recommendations can be made:-

- Similar study can be repeated in ward of the hospitals.

- Similar study can be repeated by increasing sample size.

- Similar study can be conducted by using other teaching strategies like instructional module, information booklet etc.

\section{Acknowledgement}

We are thankful to BSc Nursing Students 2015 batch of Hitech Nursing college, Technical support \& co-operation.

\section{References}

[1] Basvanthappa, BT (2009) Nursing Research, Jaypee brothers Medical Publishers, New Delhi.

[2] Burke J P. Infection control-A problem for patient safety Engl J Med. 2003;348(7):651-656 Crouzet J, Bertrand X, Venier A G, Badoz M, Huson C, Taba D.J HospInfection.2007; 67(3): 253-57

[3] Getliffe K,Newton T. Catheter-associated urinary tract infection in Primary and community health care. Oxford J.2006;35(5):477-81.

[4] Parker D, Callen L, Harwood J, Thompson D L, Wilde M, Gray M.Nursing interventions to reduce the risk of catheter associated urinary tract infection.part1: Catheter selection. J. Wound ostomy continence Nurs.2009; 36(1):23-34.

[5] Healthcare Infection Control Practices Advisory Committee (HICPAC).Guideline for prevention of catheter associated urinary tractinfections, 2009.

[6] Nicolle L. The Prevention of Hospital-Acquired Urinary Tract Infection. Clinical Infectious Diseases. 2008;46251-3 